\title{
Collaboration, Adaptation, and Scaling: Perspectives on Environmental Governance for Sustainability
}

\author{
Michael Schoon ${ }^{1, *}$ and Michael E. Cox ${ }^{2}$ \\ 1 School of Sustainability, Arizona State University, Tempe, AZ 85281, USA \\ 2 Environmental Studies Program, Dartmouth College, Hanover, NH 03755, USA; \\ Michael.E.Cox@dartmouth.edu \\ * Correspondence: michael.schoon@asu.edu
}

Received: 23 February 2018; Accepted: 25 February 2018; Published: 2 March 2018

\begin{abstract}
In preview of the special issue on "Environmental Governance for Sustainability", this manuscript examines three key themes on governance and sustainability. Governance for sustainability, by its nature, requires long-enduring institutional arrangements. Given the complex adaptive systems in which governance decision-making takes place, we explore three key characteristics of successful, long-term governance. The first of these is working across scale. This includes nested institutions as well as communication and coordination both horizontally and vertically between diverse governance groups. Second, we highlight the importance of collaboration. Building on the previous point, we draw on literature from collaborative governance and co-management to emphasize how collaboration can help to build more enduring governance structures. Third, we examine the importance of adaptation and evolution in the resolution of collective action dilemmas in complex systems filled with nonlinearities, unclear causal chains, and environments in which we have less than a full understanding of the ramifications of governance actions.
\end{abstract}

Keywords: governance; collaboration; adaptation; scaling; evolution

\section{Introduction}

Fifty years ago, Garrett Hardin wrote an article entitled "The Tragedy of the Commons" [1], which became one of the most highly cited articles of all time and a course standard for environmental studies and sciences worldwide. According to common interpretations, Hardin predicts the tragic demise of natural resources unless the commons are either subdivided into individually managed parcels or the entire commons is controlled by the state. Unfortunately, many courses of study end the story here. Yet over the past 20 years, scholars have taken great strides to understanding how governance arrangements can work toward more sustainable outcomes. In line with the classic Brundtland definition of sustainable development as "development that meets the needs of the present without compromising the ability of future generations to meet their needs", we view sustainability to require long-enduring governance structures and institutional arrangements as the key. Institutional arrangements occur as formal rules and more informal norms that guide behavior in all human societies. The seminal work by Ostrom [2] figures prominently in the development of the governance approach, and as highlighted by [3], the strength of the institutional design principles approach is that it allows for a complex array of context-specific implementation of such principles; much of its power comes from its ability to generalize while allowing for local-level diversity.

Environmental governance for sustainability occurs in a complex adaptive system and requires a systems perspective. Taking such a systems perspective, the articles in this issue examine 
the governance of linked social-ecological systems (SES). Since the publication of Dietz et al. (2003) [4], "The Struggle to Govern the Commons", scholars have increasingly focused on the governance challenges inherent in such complex adaptive systems-nonlinearities and tipping points, evolving and dynamic social and ecological agents, and emergent behaviors. In dealing with such phenomena in subsequent research, scholars have identified a number of specific challenges in the sustainable governance of SESs, including: (1) working across scale and linking governance decision-makers horizontally and vertically; (2) building collaborative arrangements across political barriers to govern at the scale of the sustainability challenge; and (3) creating institutional arrangements that adapt to maintain robustness and resilience in a dynamic environment. The articles in this special issue emphasize the role that governance plays in confronting these three challenges-building a nested, collaborative, and adaptive governance structure-for any hope for sustainable outcomes. Below we share our own perspective on each of these challenges.

\section{Working across Scale}

Society faces a number of pressing environmental dilemmas-from fisheries depletion to freshwater shortages to climate change-that span scales from local to global and that will require responses at multiple levels of governance. Appropriate responses will require revisiting the notion of institutional fit: the crafting of governance arrangements at the scale of the sustainability challenge. Previous work on the fit of institutional arrangements and scaling has focused on crafting an appropriate set of rules and institutions at the appropriate scale for the specific problem. However, we see the challenges of understanding scale in environmental governance as much broader-it is essential both to analyze phenomena and governance arrangements at multiple scales and to analyze cross-scale interactions.

Most scholarship on appropriate governance arrangements for social-ecological systems currently addresses either the very local level or the broad international or global level, and the papers in this special issue run the gamut. The multi-scalar nature of SES governance is reflected in recently emerging transnational governance arrangements as well as more traditional public forms of regulation. Abbott and others' work on the "Governance Triangle" shows that private organizations-some formed and managed by business, some by civil society, and many by multi-stakeholder groupings-as well as public-private institutions, are concurrently engaged in most areas of environmental governance $[5,6]$.

Our interest in this special feature is in the identification, navigation and coordination between and across scales. Ultimately, we want to know both how to design multi-scalar arrangements that respond to the interests of stakeholders while sustainably managing complex social-ecological systems, as well as how to reduce the friction and hence transaction costs between governance arrangements at different scales, both horizontally (between institutions at the same scale) and vertically (between institutions at multiple scales). This shares some similarities with the work of regime complex scholars [7] in that institutional proliferation has led to conflicts, overlap and friction among international obligations. However, our concerns go beyond this, to consider not only interactions between international regimes but also in the "orchestration" between public and private institutional arrangements at multiple scales $[8,9]$.

Navigating within such complex governance structures extends existing work on polycentric governance. Polycentricity describes a governance system in which multiple, interacting governing bodies have autonomy to make and enforce rules within a specific policy arena and geography [10]. These authorities interact with others at similar scales horizontally and vertically. Research on polycentric governance, particularly the earlier empirical work on polycentric policing, begins to examine the coordination between governance arrangements, but the research did not explicitly examine scale more broadly [11]. One of the key claims of polycentricity theory is that better governance outcomes will result from congruence between the institutional arrangements and the problem they attempt to resolve. In effect, polycentricity attempts to match a given governance level to the scale 
of a specific problem [12]. A given governance arrangement then interacts with others engaged in related, often overlapping sets of problems both at the same scale of phenomena and at broader scales. This supposed advantage of polycentricity equates with the notion of "fit" described above, in which fit refers to system properties and institutional attributes matching [13].

The importance of vertical interlinkages between governance spheres of authority in polycentric systems received added emphasis as the importance of nested institutions became one of Ostrom's design principles of long-enduring institutional arrangements. Through this, local-level scholars increasingly emphasized the importance of nested institutional arrangements and working between and across scales in the bottom-up processes of governance [14]. At the same time, international environmental scholars began exploring nested institutions and the top-down scaling of international regimes [15]. As studies of cross-scalar institutional arrangements increasingly understood the contribution of nested institutional arrangements to robustness and sustainability [16], SES scholars incorporated these ideas of nestedness into the development of ideas of resilience, the adaptive cycle and panarchy [17]. The nature of nested institutions implicitly requires coordination across administrative, jurisdictional and political boundaries. We see this manifest in collaborative forms of governance.

\section{Collaborative Governance}

Our world today is fragmented by all types of boundaries and borders. Addressing governance challenges of coordination across these boundaries rather than unilateral decision-making requires resolving collective action dilemmas, in which a group benefits more from acting together than acting out of individual self-interest. While governance challenges have always required collective action to resolve, the need for collaboration in governance has increased due to today's fragmented yet increasingly connected world. Fragmentation occurs ecologically; habitat patches have shrunk and split over the past century, resulting in divided landscapes and species populations [18]. Social landscapes are also fragmented; current systems of governance with international, national, state, and local authorities create multiple, overlapping jurisdictional boundaries. These boundaries are further splintered by public-private divisions and boundaries between private entities. At the same time, the social and economic connectivity and inter-reliance between people has continued to grow. Social media unites strangers in common cause, allowing movements to form and progress at breakneck speeds. At the same time, it may also serve to further divide people into groups and increasing tribalism of "us versus them". Fragmentation alone does not necessitate any change from traditional top-down decision-making. However, fragmentation in combination with greater connectivity exacerbates governance challenges by creating interdependencies between actors and decision-makers, where the actions of one affects others. As a result, fragmentation combined with interconnectedness necessitates the coordination of people across boundaries in governance and decision-making. Here, coordination refers to conducting individual actions while informing the "other" about what is being done. Collaboration, in contrast, is about working together as a collective entity.

A great deal of research across a range of disciplines has focused on collaboration and cooperation. Many anthropologists recognize cooperation as a shared human trait and have identified the evolutionary forces that favored cooperation as a fundamental characteristic of Homo sapiens. Cooperation was favored because it generated economic [19] and psychological [20] advantages; it was important in the spread and evolution of human culture over millennia; this process has been referred to as cultural group selection, whereby norms that encourage prosocial behavior are spread by the comparative advantages they offer to the groups that internalize them [21]. One popular view from anthropology defines cooperation as selfless acts of sacrifice to help others and enforce commonly held values and social norms. This corresponds closely to Wilson's (2015) definition of altruism, being a behavior that "increases the fitness of the group but places the individual at a relative fitness disadvantage with the group." 
These ideas lead directly to the foundation of human cooperation and norms of reciprocity as seen from a political economy lens [22]. To be successful, humans needed to learn to trust each other and engage in reciprocal relationships based on reputations for trustworthiness. Ultimately, multiple streams of social scientific research explore how humans can and do work together to resolve collective action dilemmas [23]. This special issue draws on the economic, political, psychological and general social science literature to understand how collaboration manifests in governance.

We see collaborative governance emerging from three overlapping literatures. The first provides a systematic overview of collaborative governance, as exemplified by a review paper by [24], and draws deeply on the field of public administration. While not wholly environment-centered, it has a preponderance of environmental cases, as the authors identify environmental issues as being at the forefront of the movement toward more collaborative processes. Their overview creates a conceptual model outlining several core components to successful collaboration, including trust-building, strong leadership, a past history of collaboration or conflict, and balancing power dynamics. The authors draw on cases of public agencies working with external stakeholders. The second body of literature is on environmental collaboration as collaborative pragmatism, embodied by the book "Making Collaboration Work" [25]. The authors build a conceptual model with several themes, such as building common understandings, emphasizing collective rather individual outcomes, and focusing on institutional structure. They then test these themes across several case studies. Other literature takes a similar approach, emphasizing learning and adaptation in response to crisis [26]. The third is the literature of adaptive co-management, which has had several comprehensive reviews [27-29]. Each of these reviews lists conditions for success including key leaders, well-delineated resources, established pathways for learning, adaptive capacity, and trust. As evidenced in its name, a core feature of this literature with more emphasis than the other collaborative literature, adaptation plays a critical role. We explore the importance of adaptation in the decision-making process in the subsequent section.

\section{Adaptation and Evolution}

Much of the work on environmental governance, including the more specific work on adaptive environmental governance, does not engage explicitly with an evolutionary lens. This is unfortunate, as we see a strong consilience between this research program and this perspective. An evolutionary process is well defined and contains widely accepted principles and components. As such, viewing social-ecological adaptation as an evolutionary process serves as a likely candidate for clarifying exactly what is meant by adaptation in environmental governance. An evolutionary process is one that involves the following three steps: (1) generation of variation among a population of entities; (2) selection on this variation by a selective environment; and (3) a process of inheritance whereby the results of the selective process are carried forward.

The evolutionary framework usefully complements much of the work that was just discussed. Ostrom's own argument regarding institutional design principles is an evolutionary argument of the kind frequently proposed by proponents of cultural group selection. Given variation in cultural traits such as the institutions used by a group to manage a commons, we can expect differential rates of survival of the groups over time, insofar as such institutions are critical in maintaining each group via the commons on which it depends. This is the implicit perspective behind Ostrom's [2] analysis of long-lasting community-based natural resource management (CBNRM) systems. Essentially, Ostrom's analysis presumed that long-lasting communities had gone through a selective process as a basis for inferring that the resultant institutional traits have important adaptive qualities. In the context of CBNRM, the selective environment consists of the social dilemmas posed by the commons on which communities depend. This idea is behind the more general association between longevity and sustainability. Supporting this interpretation, [3] argue that the design principles that Ostrom [2] produced in her seminal study in fact align well with the conditions that are needed to favor group-level selection and subsequently the evolution of collective action. 
Using the same selective logic, the evolutionary framework also enables governance scholars to make predictions in the same way that evolutionary biologists do. If a biologist knows enough about the critical features of a selective environment, then she will be able to predict important features of the species that will be found there, based on the usually correct assumption that such species will have had to adapt to this selective environment. If we know enough about the selective environment faced by a group of natural resource users, then this enables us to make predictions of what we will find based on our understanding of what features would be selected for in this historical environment.

The evolutionary framework also echoes a point made in much of the work on adaptation; that such adaptations are specific to a particular circumstance. This is also seen in work on resilience that emphasizes that we must talk about "resilience to what." Evolution is a process of adaptation to a particular selective environment, referred to as the "environment of evolutionary adaptedness (EEA)" [30]. The fitness that an adapted individual has is not so much a characteristic of the individual as it is a description of the relationship between that individual and its social-ecological environment. If that environment changes, the past adaptations may no longer be adaptive. In some cases, an evolutionary mismatch may occur, in which the selective environment of an entity changes to an extent that traits that increase fitness in a previous selective environment are now maladaptive.

This idea of a mismatch between an adapted behavior and the current selective environment resonates strongly with the notion of "fit" as described earlier, and this connection emphasizes the ubiquitous importance of this issue in human-environment interactions. One of the main challenges that arises from modern human-environment interactions is the human imposition of environments that diverge strongly from other species' EEAs (such as the constructions of roads or dams). We also impose novel selective pressures on human communities that diverge from their social EEAs: one of the main findings of much current work on local environmental governance is that communities of natural resource users that have persisted through a rigorous historical selective environment now face a mismatch between their evolved traditions and norms and what is selectively advantageous in a modern, highly interconnected world. As their current social environment departs from their social EEA, many communities around the world face a challenging evolutionary mismatch.

This observation leads us to a final point to make here, which is, how might we encourage a process of evolutionary adaptation? Much of the literature on adaptation emphasizes learning-by-doing of a sort that is reminiscent of the production of (and then selection on) diversity that is a critical part of the evolutionary process. When subjected to the guidance of an organization, this process can be seen as a "Darwin machine", this being a system, itself the product of evolution, that can guide an evolutionary process. Wilson [31], citing [32], argues for such machines when blueprint approaches to governance are insufficient: "When physical and social environments become sufficiently variable, juke-box solutions are inadequate and the only recourse is to evolve Darwin machines." A Darwin machine is a system that essentially evolves with the help of a guidance system (the "machine"). This observation closely links our view of adaptive governance with an evolutionary process, essentially equating them.

\section{Highlights and Insights from the Special Issue}

We conclude by introducing and sharing some of the main points regarding the articles in this special issue with an emphasis on how they contribute to the literature on scale, collaboration and adaptation. For simplicity, we have organized the papers in the order that they were published. Each of these stresses aspects of the core messages that we wish to introduce and elucidate in this special issue.

We begin with Faye and Ribot [33] who describe adaptation in informal governance as a mechanism for reducing vulnerability. However, what begins as a localized story of pernicious middlemen and government corruption quickly increases in complexity as multi-scalar forces are included in the analysis, linking the local economy to subnational markets to the national political level. As local communities try to adapt, the authors emphasize that the villagers' "precarity is overdetermined" (p. 15). 
Young [34] also tackles the challenges of adaptation, examining the increasingly complex challenges of modern governance. Arguing that traditional regulatory governance in world affairs struggles with three characteristics-high connectivity, nonlinear change, and emergent properties-requires more than simply augmenting static policies, Young calls for a new type of governance (Type II) during periods of transformation. He details the importance of fit across multiple scales and the need for collaboration and coordination.

Shifting in scale from the global scale to the local, Hubeau et al. [35] analyze sustainability experiments to understand how to accelerate transformations toward desired outcomes. Of particular interest to the theses of the special issue, they show how such experiments spur social learning, which, in turn, builds adaptive capacity. This process, however, is predicated upon collaboration between diverse actors in their system.

Building on the challenges of governing complex SES raised in [34], Berkes [36] provides an insightful overview of how to operationalize governance in the Anthropocene that resonates with the three main points of this introduction. First, drawing on the commons literature, Berkes shows how the institutional arrangements governing social and ecological subsystems have adapted and co-evolved over time. Second, collaboration serves as a mechanism for learning and knowledge co-production. Third, adaptive governance begins with a bottom-up approach and requires scaling up.

In contrast to Berkes call for bottom-up governance, Armstrong and Kamieniecki [37] see benefits in working within a top-down system. Similar to the Berkes and Young papers, Armstrong and Kamieniecki focus more on finding the appropriate fit to scale and the increasing role of politics in multi-level, adaptive governance. Adapting within a multi-level, multi-scalar environment requires learning through networks of collaboration.

Valkering et al. [38] move from theoretical discussions and conceptual models to empirically examining governance in local-level sustainability transitions. In particular, they focus on how to accelerate on-the-ground initiatives highlighting a number of mechanisms including upscaling efforts, partnering and collaborating, and replicating successes through inspiring other or through sprouting efforts (emigration of members to new initiatives).

Following in the tradition of [39-41], the article by Gari et al. [42] returns to the source for understanding long-enduring institutional arrangements for common-pool resource managementOstrom's design principles [2]. Relevant to this special issue, Gari et al. find that fragile SES can evolve into long-lasting institutions through a focus on adaptive features. Additionally, the article notes additional success factors beyond the original design principles.

Similar to many articles in this compilation, Huh et al. [43] take on challenges of fit between level of governance and scale of the problem in examining climate change adaptation in South Korea at the national, metropolitan and local levels. One of the biggest challenges it notes is the lack of collaboration vertically in adaptation at multiple levels. Additional adaptive capacity could emerge from tighter connections between adaptation initiatives horizontally as well.

With an emphasis on the role of building legitimacy in policymaking through global environmental assessments (GEA), Garard and Kowarsch [44] show how the interdisciplinary and collaborative nature of GEAs can improve governance outcomes. By analyzing case studies, the authors view GEAs as a bridging activity that brings diversity and multiple perspectives into governance, leading to more resilient outcomes.

Moving from adaptation to transformation, Soliev and Theesfeld [45] show how benefit sharing can bring a new vision of what sustainability means. Using examples from transboundary water disputes, pressure on global biodiversity, and competition for land through large-scale land acquisitions, the authors note that benefit sharing, in contrast to a rights-based approach, can "provide room for governance structures that facilitate adaptation and learning" (p. 18) across a wide range of scales. Such sustainable management requires collaboration across boundaries from local to international. 
Echoing the work of Young [34] and Berkes [36], Chapman et al. [46] also emphasize the inherent challenges and importance of viewing governance as a multi-scalar, complex adaptive system. As a result, the authors see a need to transform views of agricultural production systems in three ways-holistically as more than simple food production systems, through a lens of resilience rather than optimization, and engaging a broader community of stakeholders beyond a simple producer/consumer relationship.

Finally, Brown et al. [47] use coastal planning for climate change adaptation in the United Kingdom as a mechanism for exploring adaptive governance. Drawing on the literature on windows of opportunity, the authors show how windows enabling adaptation can be opened, reframed or transformed. In so doing, they showcase the need to link top-down governance in the form of legislation with bottom-up governance through grassroots action to achieve proactive adaptation.

In conclusion, our aim with this special issue was to elucidate three key aspects of environmental governance for sustainability. In particular, we have addressed the importance of a multi-scalar perspective of governance in complex adaptive systems, the role of collaboration and bringing together a diversity of perspectives and ways of knowing, and the need for constant adaptation in an ever-changing dynamic environment. The contributors to this special issue have all provided conceptual and empirical studies in support of these key points.

Author Contributions: The authors contributed equally to this manuscript.

Conflicts of Interest: The authors declare no conflict of interest.

\section{References}

1. Hardin, G. The Tragedy of the Commons. Science 1968, 162, 1243-1248. [CrossRef] [PubMed]

2. Ostrom, E. Governing the Commons; Cambridge University Press: Cambridge, UK, 1990.

3. Wilson, D.S.; Ostrom, E.; Cox, M.E. Generalizing the core design principles for the efficacy of groups. J. Econ. Behav. Organ. 2013, 90, S21-S32. [CrossRef]

4. Dietz, T.; Ostrom, E.; Stern, P.C. The struggle to govern the commons. Science 2003, 302, 1907-1912. [CrossRef] [PubMed]

5. Abbott, K.W.; Snidal, D. The Governance Triangle: Regulatory Standards Institutions and the Shadow of the State. In In Whose Benefit? Explaining Regulatory Change in Global Politics; Mattli, W., Woods, N., Eds.; Princeton University Press: Princeton, NJ, USA, 2009.

6. Abbott, K.W.; Snidal, D. Strengthening International Regulation through Transnational New Governance: Overcoming the Orchestration Deficit. Vander. J. Trans. Law 2009, 42, 501.

7. Oberthür, S.; Stokke, O.S. (Eds.) Managing Institutional Complexity: Regime Interplay and Global Environmental Change; MIT Press: Cambridge, MA, USA, 2011.

8. Abbott, K.W. The Transnational Regime Complex for Climate Change. Gov. Policy Environ. Plan. C 2012, 30, 571-590. [CrossRef]

9. Abbott, K.W. Strengthening the Transnational Regime Complex for Climate Change. Trans. Environ. Law 2013, 3, 57-88. [CrossRef]

10. Ostrom, V.; Tiebout, C.M.; Warren, R. The organization of government in metropolitan areas: A theoretical inquiry. Am. Political Sci. Rev. 1961, 55, 831-842. [CrossRef]

11. Ostrom, E.; Parks, R.B. Neither gargantua nor the land of lilliputs: Conjectures on mixed systems of metropolitan organization. In Polycentricity and Local Public Economies: Readings from the Workshop in Political Theory and Policy Analysis; University of Michigan Press: Ann Arbor, MI, USA, 1999; pp. 284-305.

12. McGinnis, M.D. (Ed.) Polycentric Governance and Development-Readings from the Workshop in Political Theory and Policy Analysis; The University of Michigan Press: Michigan, MI, USA, 1999.

13. Young, O. The Institutional Dimensions of Environmental Change: Fit, Interplay, and Scale; MIT Press: Cambridge, MA, USA, 2002.

14. Berkes, F. Cross-scale institutional linkages: Perspectives from the bottom up. In The Drama of the Commons; National Academy Press: Washington, DC, USA, 2002; pp. 293-321. 
15. Marshall, G. Nesting, subsidiarity, and community-based environmental governance beyond the local scale. Int. J. Commons 2008, 2, 75-97. [CrossRef]

16. Schoon, M.L. Governance Structures in Transboundary Conservation: How Institutional Evolution Influences Cross-Border Cooperation. Conserv. Soc. 2013, 11, 420-428. [CrossRef]

17. Schoon, M.; van der Leeuw, S. The Shift toward Social-Ecological Systems Perspectives: Insights into the Human-Nature Relationship. Nat. Sci. Soc. 2015, 23, 166-174. [CrossRef]

18. Bunn, A.G.; Urban, D.L.; Keitt, T.H. Landscape connectivity: A conservation application of graph theory. J. Environ. Manag. 2000, 59, 265-278. [CrossRef]

19. Bowles, S.; Gintis, H. A Cooperative Species: Human Reciprocity and Its Evolution; Princeton University Press: Princeton, NJ, USA, 2011.

20. Barkow, J.H.; Cosmides, L.; Tooby, J. (Eds.) The Dapted Mind: Evolutionary Psychology and the Generation of Culture; Oxford University Press: New York, NY, USA, 1995.

21. Boyd, R.; Richerson, P.J. Culture and the evolution of human cooperation. Philos. Trans. R. Soc. B 2009, 364 , 3281-3288. [CrossRef] [PubMed]

22. Ostrom, E.; Walker, J. (Eds.) Trust and Reciprocity: Interdisciplinary Lessons for Experimental Research; Russell Sage Foundation: New York, NY, USA, 2003.

23. Poteete, A.R.; Janssen, M.A.; Ostrom, E. Working Together: Collective Action, the Commons, and Multiple Methods in Practice; Princeton University Press: Princeton, NJ, USA, 2010.

24. Ansell, C.; Gash, A. Collaborative governance in theory and practice. J. Public Admin. Res. Theory 2008, 18, 543-571. [CrossRef]

25. Wondolleck, J.M.; Yaffee, S.L. Making Collaboration Work: Lessons from Innovation in Natural Resource Management; Island Press: Washington, DC, USA, 2000.

26. Goldstein, B.E. Collaborative Resilience: Moving through Crisis to Opportunity; MIT Press: Cambridge, MA, USA, 2011.

27. Armitage, D.R.; Plummer, R.; Berkes, F.; Arthur, R.I.; Charles, A.T.; Davidson-Hunt, I.J.; Wollenberg, E.K. Adaptive co-management for social-ecological complexity. Front. Ecol. Environ. 2009, 7, 95-102. [CrossRef]

28. Plummer, R.; Armitage, D. Charting the new territory of adaptive co-management: A Delphi study. Ecol. Soc. 2007, 12, 10. [CrossRef]

29. Plummer, R.; Crona, B.; Armitage, D.R.; Olsson, P.; Tengö, M.; Yudina, O. Adaptive comanagement: A systematic review and analysis. Ecol. Soc. 2012, 17, 11. [CrossRef]

30. Van Vugt, M. Evolutionary psychology: Theoretical foundations for the study of organizations. J. Organ. Des. 2017, 6, 9. [CrossRef]

31. Wilson, D.S. Darwin's Cathedral: Evolution, Religion and the Nature of Society; University of Chicago Press: Chicago, IL, USA, 2002.

32. Plotkin, H.C. Darwin Machines and the Nature of Knowledge: Concerning Adaptations, Instinct and the Evolution of Intelligence; Harvard University Press: Cambridge, MA, USA, 1994.

33. Faye, P.; Ribot, J. Causes for Adaptation: Access to Forests, Markets and Representation in Eastern Senegal. Sustainability 2017, 9, 311. [CrossRef]

34. Young, O.R. Beyond Regulation: Innovative Strategies for Governing Large Complex Systems. Sustainability 2017, 9, 938. [CrossRef]

35. Hubeau, M.; Marchand, F.; Van Huylenbroeck, G. Sustainability Experiments in the Agri-Food System: Uncovering the Factors of New Governance and Collaboration Success. Sustainability 2017, 9, 1027. [CrossRef]

36. Berkes, F. Environmental Governance for the Anthropocene? Social-Ecological Systems, Resilience, and Collaborative Learning. Sustainability 2017, 9, 1232. [CrossRef]

37. Armstrong, J.H.; Kamieniecki, S. Strategic Adaptive Governance and Climate Change: Policymaking during Extreme Political Upheaval. Sustainability 2017, 9, 1244. [CrossRef]

38. Valkering, P.; Yücel, G.; Gebetsroither-Geringer, E.; Markvica, K.; Meynaerts, E.; Frantzeskaki, N. Accelerating Transition Dynamics in City Regions: A Qualitative Modeling Perspective. Sustainability 2017, 9, 1254. [CrossRef]

39. Agrawal, A. Common resources and institutional sustainability. In The Drama of the Commons; National Academy Press: Washington, DC, USA, 2002; pp. 41-85. 
40. Baggio, J.A.; Barnett, A.J.; Perez-Ibarra, I.; Brady, U.; Ratajczyk, E.; Rollins, N.; Rubiños, C.; Shin, H.C.; Yu, D.J.; Aggarwal, R.; et al. Explaining success and failure in the commons: The configural nature of Ostrom's institutional design principles. Int. J. Commons 2016, 10, 417-439. [CrossRef]

41. Cox, M.; Arnold, G.; Tomás, S.V. A review of design principles for community-based natural resource management. Ecol. Soc. 2010, 15, 38. [CrossRef]

42. Gari, S.R.; Newton, A.; Icely, J.D.; Delgado-Serrano, M.M. An Analysis of the Global Applicability of Ostrom's Design Principles to Diagnose the Functionality of Common-Pool Resource Institutions. Sustainability 2017, 9, 1287. [CrossRef]

43. Huh, T.; Park, Y.; Yang, J.Y. Multilateral Governance for Climate Change Adaptation in S. Korea: The Mechanisms of Formulating Adaptation Policies. Sustainability 2017, 9, 1364. [CrossRef]

44. Garard, J.; Kowarsch, M. Objectives for Stakeholder Engagement in Global Environmental Assessments. Sustainability 2017, 9, 1571. [CrossRef]

45. Soliev, I.; Theesfeld, I. Reframing for Sustainability: Exploring Transformative Power of Benefit Sharing. Sustainability 2017, 9, 1486. [CrossRef]

46. Chapman, M.; Klassen, S.; Kreitzman, M.; Semmelink, A.; Sharp, K.; Singh, G.; Chan, K.M.A. 5 Key Challenges and Solutions for Governing Complex Adaptive (Food) Systems. Sustainability 2017, 9, 1594. [CrossRef]

47. Brown, K.; Naylor, L.A.; Quinn, T. Making Space for Proactive Adaptation of Rapidly Changing Coasts: A Windows of Opportunity Approach. Sustainability 2017, 9, 1408. [CrossRef]

(C) 2018 by the authors. Licensee MDPI, Basel, Switzerland. This article is an open access article distributed under the terms and conditions of the Creative Commons Attribution (CC BY) license (http://creativecommons.org/licenses/by/4.0/). 